NBER WORKING PAPER SERIES

\title{
THE POSSIBILITIES FOR GLOBAL POVERTY REDUCTION USING REVENUES FROM GLOBAL CARBON PRICING
}

\author{
James B. Davies \\ Xiaojun Shi \\ John Whalley \\ Working Paper 16878 \\ http://www.nber.org/papers/w16878
}

\author{
NATIONAL BUREAU OF ECONOMIC RESEARCH \\ 1050 Massachusetts Avenue \\ Cambridge, MA 02138 \\ March 2011
}

Earlier drafts were presented at UWO and CIGI. We are indebted to Manmohan Agarwal, Clark Leith, Chunding Li, Terry Sicular, Huifang Tian, Sean Walsh, Jing Wang, Chunbing Xing and Xiliang Zhao for their valuable comments on earlier drafts. Support from the National Foundation of Natural Science of China (Grant No.70972001), the National Science and Engineering Research Council of Canada, and the Ontario Research Fund is gratefully acknowledged. The views expressed herein are those of the authors and do not necessarily reflect the views of the National Bureau of Economic Research.

NBER working papers are circulated for discussion and comment purposes. They have not been peerreviewed or been subject to the review by the NBER Board of Directors that accompanies official NBER publications.

(C) 2011 by James B. Davies, Xiaojun Shi, and John Whalley. All rights reserved. Short sections of text, not to exceed two paragraphs, may be quoted without explicit permission provided that full credit, including $($ ) notice, is given to the source. 
The Possibilities For Global Poverty Reduction Using Revenues From Global Carbon Pricing James B. Davies, Xiaojun Shi, and John Whalley

NBER Working Paper No. 16878

March 2011

JEL No. O19,Q56

\begin{abstract}
$\underline{\text { ABSTRACT }}$
Global carbon pricing can yield revenues which are large enough to create significant global pro-poor redistributive opportunities. We analyze alternative multidecade growth trajectories for major global economies with carbon tax rates designed to stabilize emissions in the presence of both continued country growth and autonomous energy use efficiency improvement. In our central case analysis, revenues from globally internalizing carbon pricing rise to $7 \%$ and then fall to $5 \%$ of gross world product. High growth in India and China is the major equalizing force globally over time, but the incremental redistributive effects that can be achieved using global carbon pricing revenues are large both in absolute and relative terms. Revenues from carbon pricing depend on growth and energy efficiency improvement parameters as well as on the price elasticity of demand for fossil fuels.
\end{abstract}

James B. Davies

The University of Western Ontario

Department of Economics

Social Science Centre, Room 4071

London, Ontario, Canada, N6A 5C2

jdavies@uwo.ca

Xiaojun Shi

School of Economics and Management

Beijing University of Aeronautics and Astronautics

Beijing, 100191, P.R.China

sxjstein@yahoo.com.cn

\author{
John Whalley \\ Department of Economics \\ Social Science Centre \\ University of Western Ontario \\ London, ON N6A 5C2 \\ CANADA \\ and NBER \\ jwhalley@uwo.ca
}




\section{Introduction}

In this paper, we present numerical simulation results which explore the potential global redistribution impacts of revenues raised by full global carbon pricing over several decades as global growth continues. We assume a target of stabilizing emissions globally such that temperature increase does not exceed $2^{\circ} \mathrm{C}$ above preindsutrial level by 2105 . We assess the impacts on both absolute and relative global poverty of redistributing the associated revenues in various ways. An obvious political impediment for such mechanisms is resolving whether full carbon pricing can only be administrated as a series of separate national schemes with revenues remaining in countries, or whether a single global revenue agency could realistically collect and redistribute revenues. While perhaps Utopian, the possibility of such an agency creates a new opportunity for significant redistribution to the global poor.

Our simulations cover the period from 2015 to 2105, and assume stable energy demand elasticities and energy efficiency improvement factors. Using an elasticity carbon pricing method, we calculate implied revenues of roughly $6 \%$ of Gross World Product (GWP) on average across the whole time period. Simulations suggest that continued higher growth in lower wage large population economies, and especially China, will be a powerful force driving global inequality reduction. But carbon pricing financed redistribution can also play a role in significantly reducing both global inequality and absolute poverty. If revenues are redistributed to countries on an equal per capita basis, the global Gini coefficient falls, on average, by an extra $4.9 \%$ over the period $2015-2105$, and the bottom decile share increases by a further $21.2 \%$. Furthermore, if carbon pricing revenues are used to directly fund transfers to the poor within countries, our simulations suggest that using tax revenues in this way could also bring significantly more individuals and households globally above global poverty lines. 


\section{Background}

Thus far in debate on global carbon emissions reduction the focus of any special arrangements for poorer developing countries has been on the interpretation of the "common but differentiated responsibilities" commitment in favor of developing countries in the 1994 United Nations Framework Convention on Climate Change (UNFCCC). The focus of this debate has been on smaller emissions reductions by lower income countries. The debate should also (and perhaps principally) include the use of carbon pricing revenues to help the poor.

Global carbon pricing (effectively a carbon tax) is clearly a superior policy option for global redistributive purposes than carbon cap-and-trade systems, now in place in several countries, and particularly in Europe. Cap-trade systems fall short of carbon pricing on two grounds. One is that they collect small amounts of revenue and hence can only fund small direct redistributive transfers. Moreover, they are basically within-country or within-region mechanisms which have limited global redistributive effects.

In what follows we explore how far full global carbon pricing can reduce relative inequality and global absolute poverty globally. ${ }^{1}$ We assume growth trajectories for major global economies and targets of emission stabilization, and assume rates of improvement in emissions efficiency of energy use. We assume that growth in national economies continues in the decades ahead, and that global carbon pricing which meets targets for emissions reductions to stabilize global temperature is implemented. We then assume that global carbon revenues from full global carbon pricing are used for poverty reduction purposes rather than lowering other existing taxes.

\section{Base Case and Counterfactual Scenarios}

The time period covered by our simulations is 2015 through 2105. Our base case is a business-as-usual (BAU) scenario without carbon emissions reductions for the global economy between 2015 and 2105. This BAU scenario is similar to the base case of

\footnotetext{
${ }^{1}$ Other authors suggest using carbon pricing revenues for other purposes. One recent proposal is that of Grubb and Droege (2010) who suggest using such revenues in Europe for debt reduction.
} 
Nordhaus' RICE-2010 model (Nordhaus, 2010). Our counterfactual scenario implies an emissions target aimed at controlling global temperature change to less than $2^{\circ} \mathrm{C}$ by 2105. To be consistent with the BAU scenario, our counterfactual scenario also follows Nordhaus' RICE-2010 model (Nordhaus, 2010), using his "limit to $2^{\circ} \mathrm{C}$ " case.

In our analysis of carbon pricing impacts we use a business as usual (BAU) or base case given by projections out to 2105 developed by Nordhaus (2010). Three variables are at the heart of our analysis: growth in country/regional incomes, country and global emissions; and country and global population growth. Figure 1 sets out the paths of these three variables at the global level for the period 1960 to 2008 .

Figure 1: Historical Trajectories of GWP, Population and $\mathrm{CO}_{2}$ Emissions, 1960 - 2008

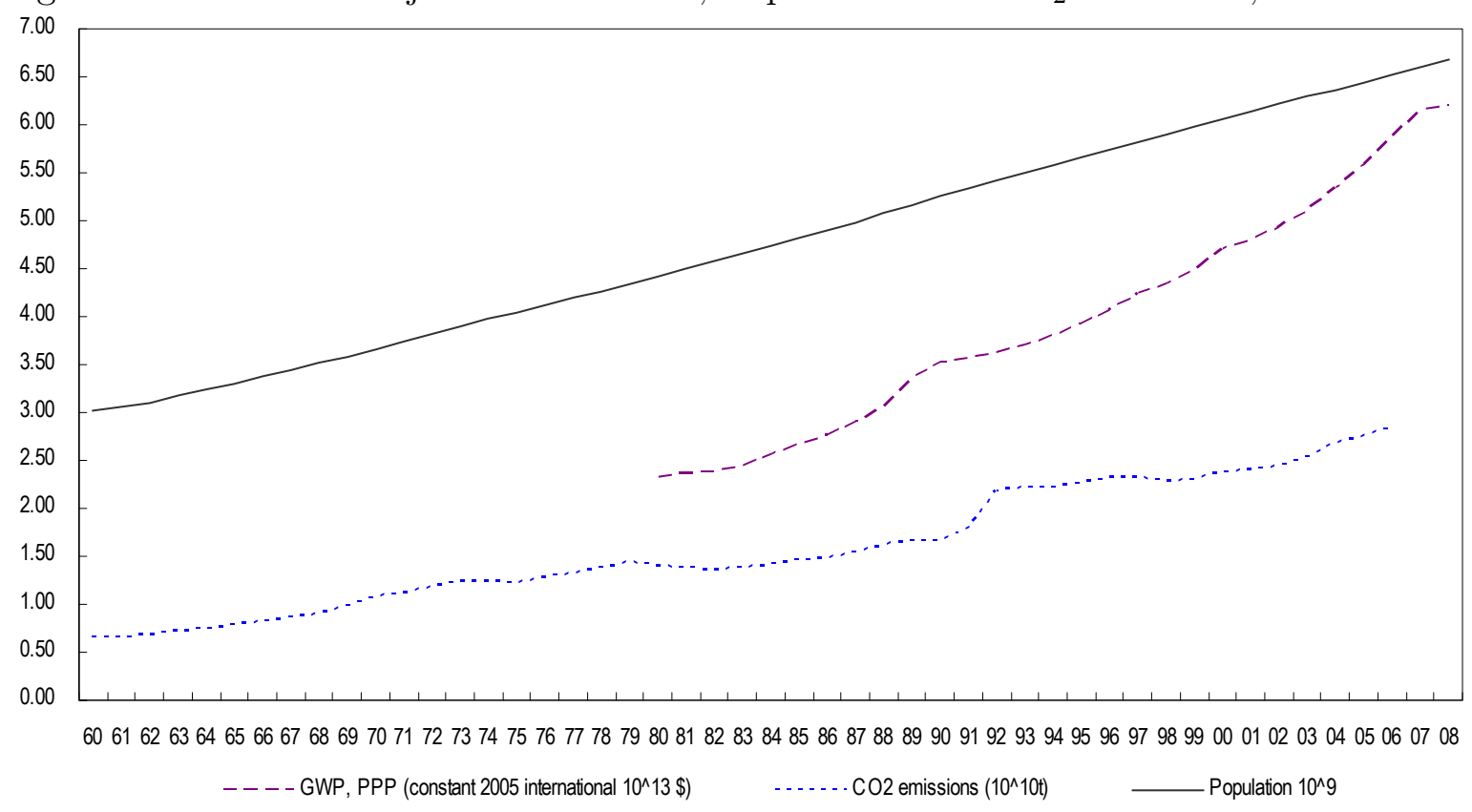

Note: GWP is Gross World Product.

Purchasing Power Parity (PPP) GDP by country/region in the projections is given by a modified neoclassical production function used by Nordhaus. Total output for 12 regions $^{2}$ is projected by Nordhaus using a partial convergence model, and regional outputs are then aggregated to a world total. We use Nordhaus' adjusted projection GDP which accounts for climate damages as our BAU scenario. Population projections

\footnotetext{
${ }^{2}$ Theses 12 regions are USA, EU, China, Russia, Japan, India, Africa, Latin America, Eurasia, MidEast, Other Asia and Other High Income regions.
} 
used by Nordhaus involve a simplified logistic-type specification in which the growth of population by region in the first decade is given and growth rates decline such that the total global population approaches a limit of 8.5 billion $^{3}$.

Emissions in these scenarios are projected using a series of geophysical equations described in Nordhaus (2008). His emissions projections are developed using different methods and more recent data than the IPCC SRES scenarios ("Special Report on Emissions Scenarios" for IPCC, 2000) ${ }^{4}$.

The Nordhaus projections are for a 12-region classification. Since our later calculations of poverty impacts of carbon pricing are at a country level, we need to decompose the regionally aggregated data from Nordhaus. We assume that each country's shares of GDP, population and emissions within a region are constant at 2005 levels, the benchmark year in our analysis. Using this assumption, we decompose the regional aggregation in these scenarios into country-level projections for 189 countries.

Table 1 summarizes predicted global trajectories of our three central variables from 2015 through 2105 in both the BAU scenario and the counterfactual scenario in which global temperature increase is limited to $2^{\circ} \mathrm{C}$ up to 2105 .

\footnotetext{
${ }^{3}$ Nordhaus (2008) notes that this projection is slightly below the middle estimate of the United Nations long-term projection (UN, 2004), but is calibrated to match the International Institute of Applied Systems Analysis (IIASA) projections (IIASA, 2007).

${ }^{4}$ The Nordhaus emissions projections are toward the low end of the SRES range until the middle of the twenty-first century and then rise relative to some of the lower SRES scenario estimates.
} 
Table 1: BAU and Counterfactual Scenarios For GWP, Population and $\mathrm{CO}_{2}$ Emissions Over 2015 - 2105 Implied by Nordhaus (2010)

\begin{tabular}{lrrrrrrr}
\hline & 2005 & 2015 & 2035 & 2055 & 2085 & 2105 \\
\hline & & \multicolumn{7}{c}{ BAU Scenario } \\
GWP after damages before abatement, \$trill & 55.20 & 80.75 & 145.90 & 224.44 & 362.94 & 473.41 \\
Population (millions) & 6407.27 & 7169.69 & 8374.06 & 8897.53 & 8905.66 & 8888.67 \\
Total carbon emissions (GTC per year) & 9.57 & 11.51 & 14.08 & 15.87 & 17.83 & 19.19 \\
& & \multicolumn{7}{c}{ Counterfactual Scenario } \\
GWP (net of damages and abatement, \$trill) & 55.20 & 80.66 & 145.40 & 222.52 & 361.73 & 478.41 \\
Population (millions) & 6407.27 & 7169.69 & 8374.06 & 8897.53 & 8905.66 & 8888.67 \\
Total carbon emissions (GTC per year) & 9.57 & 8.73 & 7.56 & 3.38 & 0.27 & 0.17 \\
\hline
\end{tabular}

Note: i) GWP is Gross World Product.

ii) In the counterfactual scenario, global temperature increase is limited to $2^{\circ} \mathrm{C}$ or less up to 2105 .

iii) \$trill refers to trillion 2005 PPP dollars.

iv) GTC refers to gig metric tonnes of carbon.

\section{Revenues From Carbon Pricing in Counterfactual Analysis}

We use counterfactual analyses around the scenarios set out above to evaluate the potential redistributive impacts of alternative full global carbon pricing schemes aimed at internalizing the global externality from carbon emissions. A single global price for all emissions of carbon dioxide and other greenhouse gases, to be administrated by a single global agency collecting the revenues, that is effectively a global carbon tax, is assumed. Revenues are assumed to be deployed for alternative global redistributive purposes by this global agency.

We assume that global carbon prices are set so as to achieve various target levels of emissions. We assume growth rates for economies around the world, and a value for the price elasticity of demand for fossil fuels. Given growth rates we then calculate the carbon prices needed to achieve particular targets for annual emissions which in turn maintain temperature change within key bounds.

A key element in our calculations of redistributive impacts is the level of carbon prices 
needed as these levels are critical in determining revenue. A variety of carbon pricing assumptions are adopted in the literature as part of the global policy regime needed to achieve various emissions targets (Stern, 2006; Nordhaus, 2008; Boyce and Riddle, 2009, among others). These range from tens to thousands of dollars per tonne of carbon. Here, we calculate the carbon pricing needed globally to achieve a bound on global temperature change of $2^{\circ} \mathrm{C}$ by 2105 . This gives us carbon prices for our central cases. These vary as we use different estimates of the price elasticity of demand for fossil fuels since price based instruments are used to achieve the global emissions reduction target.

The price elasticity of demand for energy is key in calculating our level of carbon pricing, and we use literature based estimates of the elasticity of the demand for fossil fuels in our calculations. Most of these estimates can be grouped into one of three classes: near zero, near negative unity (minus one) or around minus one-half (Lipow, 2010). Komanoff (2010) estimates separate demand price-elasticities by energy sources, - 0.7 for electricity, - 0.4 for gasoline, - 0.6 for jet fuel, and - 0.5 for other fuels. US shares of consumption across these energy categories are roughly $40 \%, 21 \%, 4 \%$ and $35 \%$ (Komanoff, 2010), and this yields an average elasticity across sources of - 0.55. We use - 0.5 as our central global price elasticity of demand for fossil fuels. We assume this elasticity is constant over time and over the interval of possible demands, $(0,+\infty)$. As a result, each projection year assumes a constant own-price elasticity.

Another key element in our calculations of carbon pricing needed to achieve targets for emissions reduction is the likely energy efficiency improvement over time either from behavioral changes in energy consumption or technology upgrading. The International Energy Agency (IEA) has issued three reports on worldwide energy efficiency. According to the latest (IEA, 2008), the energy efficiency improvement achieved for 16 IEA countries $^{5}$ over the period 1990 - 2005 averaged only $0.9 \%$. We assume that this rate of improvement remains constant after 2005.

Developing and transitional economics experienced larger energy efficiency improve-

\footnotetext{
${ }^{5}$ These are Australia, Austria, Canada, Denmark, Finland, France, Germany, Italy, Japan, Netherlands, New Zealand, Norway, Sweden, Switzerland, UK, and US. They comprise the greater part of the OECD in terms of population and GDP.
} 
ments over the same period. For instance, in China, the index of Total Final Energy Consumption per Unit of GDP fell from 100 in 1990 to 40 in 2005, averaging roughly a $4 \%$ energy efficiency improvement per year. Similarly, India also saw high average energy efficiency improvements of roughly $2.9 \%$ per year during the same period. Data for other developing countries outside the IEA are limited. We assume a 3\% energy efficiency improvement rate for the rest of the world except the 16 IEA countries included above. These 16 IEA countries consumed around $50 \%$ of world primary energy in 2005 (UN, 2007, table in Box 1 on page 10). Combining these two groups yields an estimate of $2 \%$ worldwide energy efficiency improvement per year. In our baseline analysis, we assume this same energy efficiency improvement factor applies for both the BAU and the counterfactual cases targeted to achieve a $2^{\circ} \mathrm{C}$ temperature change cap. We then relax this assumption in sensitivity analysis.

The third element is backstop technology progress including carbon absorption through sinks, capture and storage; and innovation of other renewable non-carbon energy as substitution to fossil fuels when the carbon prices are high. This element is implicitly expressed in Nordhaus' (2008 and 2010) geophysical and industrial emissions equations. It plays a crucial role in explaining how quite small emissions could sustain the world economy toward the end of the simulation period, such as from 2085 to 2105 . Here we model this element explicitly, using a constant annual rate of emission reduction per unit of energy, $\lambda$, assumed equal to $4 \%$.

Given the assumed values of $E_{\tau}$ and $E_{\tau}^{*}$, we solve for $D_{\tau}$ and $D_{\tau}^{*}$ and then use a price elasticity, efficiency improvement factors and technological progress in carbon capture, we next calculate the carbon price levels and revenues needed to achieve emissions reductions consistent with a global temperature change target of $2^{\circ} \mathrm{C}$. The base date is $t_{0}$ and the date for target temperature change is $\tau$. Emissions both at time $t_{0}$ and $\tau$ for the BAU and counterfactual cases are as in Table 1. We denote BAU and counterfactual emissions as $E_{\tau}$ and $E_{\tau}^{*}$ respectively. Energy efficiency improves from $f_{t_{0}}$ at time $t_{0}$, to $f_{t_{0}}\left[e^{\delta_{i}\left(\tau-t_{0}\right)}\right]$ at time $\tau$, where $\delta_{i}(i=0,1)$ denotes the global efficiency improvement factor assumed in both the $\operatorname{BAU}(i=0)$ and counterfactual $(i=1)$ cases. In addition, the emissions deflation factor due to backstop technology progress is $e^{-\lambda\left(\tau-t_{0}\right)}$. We further assume a 
conversion from fossil fuels to carbon emissions coefficient, denoted by $c$, which is fixed over time.

We thus have

$$
\begin{aligned}
& E_{\tau}=D_{\tau} \cdot f_{t_{0}}\left[e^{\delta_{0}\left(\tau-t_{0}\right)}\right] \cdot c, \\
& E_{\tau}^{*}=D_{\tau}^{*} \cdot f_{t_{0}}\left[e^{\delta_{1}\left(\tau-t_{0}\right)}\right] \cdot c \cdot e^{-\lambda\left(\tau-t_{0}\right)},
\end{aligned}
$$

where $D_{\tau}$ and $D_{\tau}^{*}$ are fuels demands at $\tau$ in BAU and counterfactual cases respectively. After solving $D_{\tau}$ and $D_{\tau}^{*}$, we can then use a price elasticity of demand estimate to calculate the carbon prices needed to achieve the given target.

We use an equivalent carbon tax (ECT) for carbon based fossil fuels energy sources, since there is only an elasticity of demand of fuels, but no carbon demand elasticity as such. We denote the incremental component of the price of fossil fuels (effectively a tax) due to full global carbon pricing as $r_{E}$, giving

$$
P_{\tau}^{*}=\left(1+r_{E}\right) P_{\tau},
$$

where $P_{\tau}^{*}$ and $P_{\tau}$ are the prices of fuels at $\tau$ for the counterfactual case (incorporating carbon pricing) and the BAU case respectively. The elasticity of demand for fossil fuels at time $\tau$ is given by

$$
\frac{\left(D_{\tau}^{*}-D_{\tau}\right) / D_{\tau}}{\left(P_{\tau}^{*}-P_{\tau}\right) / P_{\tau}}=\eta_{\tau}
$$

As the efficiency improvement in the counterfactual case is the same as in our BAU case (i.e., $\delta_{1}=\delta_{0}$ ), substituting (1) through (3) into (4) gives

$$
r_{E}=\frac{E_{\tau}^{*} e^{\lambda\left(\tau-t_{0}\right)}-E_{\tau}}{\eta_{\tau} E_{\tau}} .
$$

In later sensitivity analysis, we relax the similar country efficiency improvement factor treatment and let $\delta_{1}>\delta_{0}$. This implies the value of the elasticity is equal to

$$
\eta_{\tau}^{e}=\frac{E_{\tau}-E_{\tau}^{*} e^{\lambda\left(\tau-t_{0}\right)} \cdot e^{-\left(\delta_{1}-\delta_{0}\right)\left(\tau-t_{0}\right)}}{E_{\tau}-E_{\tau}^{*} e^{\lambda\left(\tau-t_{0}\right)}} \times \eta_{\tau} .
$$

and substituting this elasticity into (3) gives

$$
r_{E}^{e}=\frac{E_{\tau}^{*} e^{\lambda\left(\tau-t_{0}\right)}-E_{\tau}}{\eta_{\tau}^{e} E_{\tau}}
$$


where $r_{E}^{e}$ is the incremental fossil fuels price from carbon pricing in the case using different country energy efficiency improvement factors.

Finally, the global full carbon price, $\Gamma$, measured as a PPP 2005 International $\$ /$ metric tonne of $\mathrm{CO}_{2}$ can be calculated by

$$
\Gamma=\beta \times r
$$

where $\beta$ is the fixed coefficient relationship between gallons of fossil fuel and metric tonnes of $\mathrm{CO}_{2}$; and $r$ takes on the alternatives of $r_{E}$ and $r_{E}^{e}$ for uniform and country different energy efficiency improvement cases. Using an average price of gasoline over the last 10 years of $\$ 2 /$ gallon (EIA, 2010), yields an estimated value of $\beta$ (see also Komanoff's (2010) CTC Carbon Tax Model).

Our method of determining levels of carbon pricing deviates from Nordhaus (2008 and 2010), even though our emissions data, in both BAU and counterfactual cases, are the same. Nordhaus' carbon pricing schemes yield carbon revenues less than $2 \%$ of Gross World Product (GWP) on average. These imply a fossil fuels price elasticity of demand that is seemingly very much larger than estimates in the empirical literature.

The elasticity method set out above yields a carbon price for global emissions each period assuming all emissions are included and treated equally. Table 2 presents our calculations carbon prices at different dates. These imply that, over the next 100 years, carbon prices would rise gradually from $\$ 85 / \mathrm{TCO}_{2}$ in 2015 to $\$ 1061 / \mathrm{TCO}_{2}$ by 2085 , after which they would decline to $\$ 819 / \mathrm{TCO}_{2}$ in 2105 .

The revenues raised by the carbon pricing schemes are then assumed to be transferred to lower income countries in various ways. Table 2 suggests that revenues from carbon pricing in our central case are $4.5 \%$ of GWP in 2015 rising to a peak of $7.9 \%$ in 2055 and declining then to $5.7 \%$ in 2105 .

Figure 2 indicates that the revenues in absolute values increase over time from 2015 to 2105 , despite the fact that the revenue share of GWP peaks at $7.90 \%$ in 2055 . This is due to two reasons. On one hand, the difference in carbon emissions between the BAU and counterfactual scenarios is relatively stable from 2055 to 2105 , which prevents revenues over these years from growing sharply. On the other hand, GWP over the period between 
Table 2: Full Global Carbon Pricing and Associated Revenues

\begin{tabular}{cccccc}
\hline & 2015 & 2035 & 2055 & 2085 & 2105 \\
\hline Carbon Pricing & 85 & 104 & 200 & 1061 & 819 \\
Revenues & $3.60 \times 10^{12}$ & $9.01 \times 10^{12}$ & $1.77 \times 10^{13}$ & $2.55 \times 10^{13}$ & $2.76 \times 10^{13}$ \\
Shares of GWP & $4.5 \%$ & $6.3 \%$ & $7.9 \%$ & $7.0 \%$ & $5.7 \%$ \\
\hline
\end{tabular}

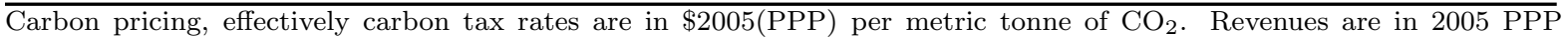
dollars. Shares refer to the ratio of revenues to the projected GWPs in respective years. 22 smaller countries are dropped in our dis-aggregating regional projections of Nordhaus' (2010) RICE-2010 model into country level data because of missing data in the benchmark year of 2005 .

2055 and 2105 continues to grow, while carbon emissions are curtailed to lower levels.

We thus see decreases in the share of carbon tax revenue in GWP from 2055 to 2105.

Figure 2: Revenues from Carbon Pricing in the Central Case

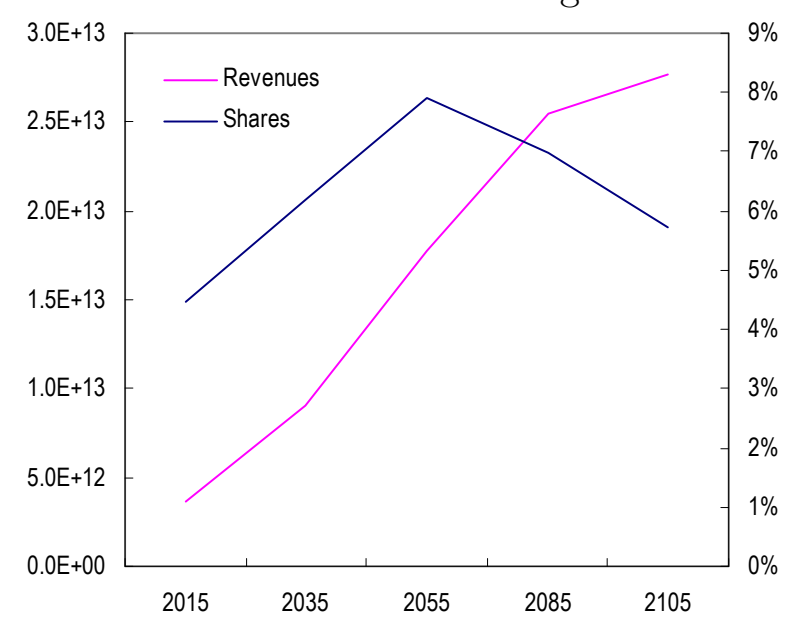

Note: Revenues are carbon pricing revenues in absolute values.

Share is carbon pricing revenues as percentage of GWP.

\section{Data Sources, Redistribution Schemes and Method- ology for Counterfactual Analysis}

\subsection{Data Sources}

For counterfactual analysis of the potential impacts of full global carbon pricing on global poverty reduction, we need data on current emissions, population, global income 
distribution, and revenues from carbon pricing over 2005 to 2105, with an international poverty line specified. Our benchmark year is 2005 .

For the benchmark year, our GDP, carbon emissions and population data at country level all draw on the World Bank's World Development Indicators (WDI) database. The WDI table has 211 countries in total. We only use 189 countries, dropping 22 due to missing data in the benchmark year.

Beyond the benchmark year, projected GDP (in \$2005PPP), carbon emissions and population data at the 12 region level follow Nordhaus (2010). Under the assumption that each country's shares of GDP, emissions and population within its region are fixed at the levels of the benchmark year, we can generate country level data. The aggregate data does not include the 22 countries that were dropped.

Using data on country emissions for each projection year, we allocate the tax burden from carbon pricing reflected in the global revenues shown in Table 2 to each country according to its share of global emissions. Ideally, to quantify redistributive impacts here, we need data on global and within-country income distribution over the time period 2005 to 2105 . While recent and comprehensive data on poverty and income distribution are available from the World Bank, we do not know the pattern of emissions by income within countries and have no basis for projecting future changes in national income distributions other than those caused by our tax/transfer scheme. ${ }^{6}$ However, the BAU and counterfactual projections do provide a path for each country's GDP per capita from 2005 to 2105 . This provides a basis for projecting changes in income inequality between countries, which is the most important component of global income inequality.

Despite the above difficulties, we can generate projections of both global income inequality in the BAU and counterfactual scenarios. To project changes in inequality between countries we use per capita GDP (in 2005 PPP dollars) as a proxy for per capita personal income. This reflects the non-availability of personal income projections for

\footnotetext{
${ }^{6}$ The information we need on income distribution is available through the World Bank's World Development Indicators. Information on poverty was obtained through PovcalNet, a product of the World Bank's Development Research Group. It is an interactive computational tool that estimates the extent of absolute poverty in the world. It can be accessed freely via http://iresearch.worldbank.org/PovcalNet.
} 
2015 - 2105. Using GDP and population projections from Nordhaus (2010) taken to the country level, we project the proxy income for each country. Within countries we fit a lognormal distribution for income in 2005 on the basis of World Bank data, as explained below. For later years we assume that these within-country distributions only change by scale, that is relative inequality of income measured before our tax/transfer schemes remains the same as in 2005 within each country. To obtain projections of the global income distribution after our tax/transfer schemes apply we assume that emissions are proportional to income within countries. The ratio of emissions to income is, however, allowed to vary across countries according to the Nordhaus projections along the BAU and counterfactual paths.

\subsection{Redistribution Schemes}

We use two revenue redistribution schemes in our counterfactual analysis. The first redistributes equally on a per capita basis all over the world. This is the simplest approach. Our later calculations and analysis mainly focus on this alternative. Our second scheme allocates a larger share of revenues on a global scale to the extreme poor than in the equal per capita scheme. The extreme poor are those living below the World Bank's updated international poverty line which is discussed in section 5.3. Using this scheme, we seek to find whether it is possible to move all the extreme poor above the poverty line by 2015 using only a carbon pricing and transfer scheme, and how large a share of revenue needs to be dedicated to the extreme poor in order to realize this ambitious goal.

\subsection{Methodology}

We analyze the potential impacts of global carbon tax/transfer schemes in reducing both relative inequality and absolute poverty on a global scale. For relative inequality, we focus on changes in the global Gini coefficient and the shares of the top and bottom deciles. Since the Gini coefficient tends to be relatively insensitive to changes in the tails it is advisable to complement it with the top and bottom decile shares.

The Gini coefficient can be decomposed into within country, between country, and 
remainder terms as follows (see e.g. Mookherjee and Shorrocks, 1982):

$$
G=\sum_{k} v_{k}^{2} \vartheta_{k} G^{k}+\frac{1}{2} \sum_{k} \sum_{h} v_{k} v_{h}\left|\vartheta_{k}-\vartheta_{h}\right|+R,
$$

where $G^{k}$ is the Gini coefficient within country $k, v_{k}$ is country $k$ 's proportion of global population, $\vartheta_{k}$ is its mean income relative to that of the whole world, and the remainder' term $R$ reflects the interaction effect due to overlaps between the income distributions in different countries. We project future changes in global income distribution by making separate projections for the three decomposition components. We use 2002 as our calibration year. According to Milanovic (2009), this is the latest year having household survey data and a reliable global Gini coefficient estimate.

As explained above, we assume that relative inequality of income before the tax/transfer scheme, and therefore the Gini coefficient, stays fixed over time within countries. The WDI database provides Gini coefficients for 143 of our 189 countries. Gini coefficients for the 46 countries with missing values are assumed equal to the arithmetic average. This procedure gives us the first term in equation 9 for income before the tax/transfer scheme. The second term in equation 9 corresponds exactly to the "international" or Concept 2 inequality of Milanovic $(2005,2009)$. That is, it is the global Gini coefficient one would obtain if there were zero inequality within countries. Finally, the value for $R$ can be calibrated using the Gini coefficient for the global income distribution of 0.7 in 2002 found by Milanovic (2009) using 2005 PPP exchange rates. We further assume that the value for $R$ stays fixed over the projection years. Equipped with values for the "within" term and $R$, we are able to specify the global Gini coefficients of income before the carbon tax and transfer for each projection year.

To compute within-country Gini coefficients for income after the carbon tax and transfer we proceed as follows. We denote the average (proxy) income of country $k$ as $\bar{y}_{k}$, the effective carbon tax rate as a proportion of (proxy) income in country $k$ as $\tau_{k}$, and the per capita transfer as $D_{k}$. The Gini coefficient of country $k$ after tax and redistribution, 
$G^{\prime k}$, is $^{7}$

$$
G^{\prime k}=G^{k} \frac{\left(1-\tau_{k}\right) \bar{y}_{k}}{\left(1-\tau_{k}\right) \bar{y}_{k}+D_{k}}
$$

Thus, we have a procedure for projecting global Gini coefficients for income, both before and after the carbon tax and transfer schemes we will model, along the BAU and counterfactual Nordhaus paths from 2005 to 2105. But we would also like to know the corresponding shares of the top and bottom deciles plus the absolute poverty levels through time. In order to get this additional information we need complete world distributions of income for each run, year, and income measure. It would be possible to build up the world distribution by aggregating individual estimates of the full income distribution within each country. However, this is both laborious and would reflect false precision since we cannot predict changes in the shape of the income distribution within countries before the tax and transfer.

In quantifying top and bottom deciles and absolute-poverty impacts from carbon pricing, we assume a lognormal distribution for global incomes. Denoting income as $w$, we thus assume it has the density function

$$
g(w)=\frac{1}{\sqrt{2 \pi} \sigma w} e^{-\frac{(\ln w-\mu)^{2}}{2 \sigma^{2}}} .
$$

Given a world population, $P$, the population $N_{h}$ with income no higher than $h$ is

$$
N_{h}=P \int_{0}^{h} \frac{1}{\sqrt{2 \pi} \sigma w} e^{-\frac{(\ln w-\mu)^{2}}{2 \sigma^{2}}} d w .
$$

To fully characterize this normalized function requires two parameters, $\mu$ and $\sigma$. In our calculations, we generate a world population, $P$, and GWP, $I$, in scenario projections, giving the world average income $\frac{I}{P}$ for each year under study. In addition, we also have a global Gini coefficient for each time period. Using these data, we are able to parameterize

\footnotetext{
${ }^{7}$ The Gini coefficient equals one half the ratio of the mean difference to the mean. The carbon tax alone does not affect this ratio, since it reduces the mean difference and the mean in equal proportion. By itself the transfer, on the other hand, increases the mean and reduces the Gini coefficient in inverse proportion to the change in the mean, as we see in equation 10.
} 
the function (11) applying the following two formulas for lognormal distributions (see Kemp-Bendict, 2001; also see Deaton, 2003):

$$
\begin{gathered}
\sigma=\sqrt{2} \Phi^{-1}\left[\frac{G i n i+1}{2}\right], \\
\mu=\ln \left(\frac{I}{P}\right)-\frac{\sigma^{2}}{2},
\end{gathered}
$$

where $\Phi^{-1}[\cdot]$ is the inverse cumulative distribution function of the standard normal.

In quantifying absolute poverty impacts, we next set the poverty line. We use a criterion of $\$ 1.25$ in 2005 PPP per day suggested by the World Bank as the international poverty-line (Chen and Ravallion, 2008). This must be translated into an Equivalent Poverty Line, $w_{c}$, in terms of GDP per capita. Chen and Ravallion (2008) document that with the $\$ 1.25$ poverty-line, 1.4 billion people were in poverty in 2005 . As we have world population $P$, and values of $\mu$ and $\sigma$ for 2005, we can then solve for $\ln w_{c}$ mapping into 1.4 billion in-poverty people using the inverse of equation 12 . This critical value $\ln w_{c}$ is equivalent to the $\$ 1.25$ poverty-line. For simplicity we assume that the Equivalent Poverty Line remains constant through time.

Equipped with distribution parameters and our Equivalent Poverty Line, we quantify absolute poverty reduction due to carbon pricing and revenue redistribution. Firstly, in our BAU scenario, we substitute values of $\mu, \sigma$ and $\ln w_{c}$ for each year into equation 12 to find the population in poverty without carbon pricing. Secondly, with carbon pricing and revenues redistribution, we re-calculate GDP per capita for each country and produce the new Gini and mean income accordingly. Then we repeat the first step, and substitute $\ln w_{c}$ and the new $\mu$ and $\sigma$ into equation 12 to find the population in poverty in our counterfactual scenario. The difference in the populations in poverty in these two scenarios (in-poverty population at first step minus values from the second step) reflects the impact of the carbon tax/transfer scheme in global absolute-poverty reduction. 


\section{The Global Redistributive Impacts of Carbon Pric- ing}

We next report results on the potential redistributive impacts of global revenue redeployment from full global carbon pricing. Our central carbon pricing scheme collects revenues as specified in Table 2 which are the effective carbon tax burdens allocated to each country according to its shares of global emissions at various dates. These results assume that the global price elasticity of demand for fossil fuels is -0.5 , and the annual energy efficiency improvement factors for both BAU and counterfactual cases are all $2 \%$ per year for all countries. Moreover, GDP, population and emissions growth trajectories follow Table 1.

\subsection{Relative Inequality Reduction}

We analyze global redistribution impacts in terms of global Gini coefficients and income shares of the top and the bottom deciles. Table 3 presents the results for relative global inequality reduction for our central scheme. Trends for the three inequality indicators are reported and show that global inequality would be reduced by continued growth and development, particularly in China and India. The Gini coefficient falls by around $25 \%$ in the BAU case over the projection period, from 0.6825 in 2015 to 0.5114 in 2105. The bottom decile share increases by around 2.37 times and the top decile share decreases by $31 \%$. These results do not detract from growth in the developing economies being the most powerful equalizing force which the most prominent changes in the bottom decile share among the three indicators, but the incremental redistributive impact of carbon pricing revenues remains.

The solid lines in Panel A to C of Figure 3 plot the changes in Gini coefficient, bottom decile share and top decile share across time periods. Columns with a "Carbon Pricing" heading in Table 3 present the results for the three inequality indicators after carbon pricing and transfer specified in our central scheme. In Figure 3, they are plotted in dotdash lines, with legends showing the elasticity of 0.5 used in brackets. Carbon pricing 
can play a major incremental role in global income equalization in addition to economic growth, driving increases in the bottom decile shares and decreases in the Gini and top decile shares. Among these three indicators, carbon pricing has the larger impacts on the bottom decile share, and a slight downward shift in the top decile share.

Carbon pricing increases the bottom decile share by more than 15\%. Across most projection years, carbon pricing causes an additional decrease in the Gini coefficient by $3 \%$ and, in the top decile share, by more than $4 \%$.

Table 3: Relative Inequality Reduction by Carbon Pricing

\begin{tabular}{|c|c|c|c|c|c|c|c|c|c|}
\hline \multirow[b]{2}{*}{ Year } & \multicolumn{3}{|c|}{$\underline{\text { Panel A: Gini Coefficient }}$} & \multicolumn{3}{|c|}{ Panel B: Bottom Decile Share } & \multicolumn{3}{|c|}{ Panel C: Top Decile Share } \\
\hline & $\mathrm{BAU}$ & Carbon Pring & Change & $\mathrm{BAU}$ & Carbon Pricing & Change & $\mathrm{BAU}$ & Carbon Pricing & Change \\
\hline 2015 & 0.6825 & 0.6615 & $-3.1 \%$ & 0.0035 & 0.0042 & $19.5 \%$ & 0.5526 & 0.5288 & $-4.3 \%$ \\
\hline 2035 & 0.6309 & 0.6022 & $-4.6 \%$ & 0.0054 & 0.0066 & $23.5 \%$ & 0.4955 & 0.4658 & $-6.0 \%$ \\
\hline 2055 & 0.5876 & 0.5517 & $-6.1 \%$ & 0.0073 & 0.0093 & $26.8 \%$ & 0.4513 & 0.4171 & $-7.6 \%$ \\
\hline 2085 & 0.5368 & 0.5058 & $-5.8 \%$ & 0.0102 & 0.0123 & $20.4 \%$ & 0.4036 & 0.3765 & $-6.7 \%$ \\
\hline 2105 & 0.5114 & 0.4857 & $-5.0 \%$ & 0.0119 & 0.0138 & $15.9 \%$ & 0.3813 & 0.3597 & $-5.7 \%$ \\
\hline
\end{tabular}

Figure 3: Relative Inequality Reduction by Carbon Pricing

Panel A: Gini

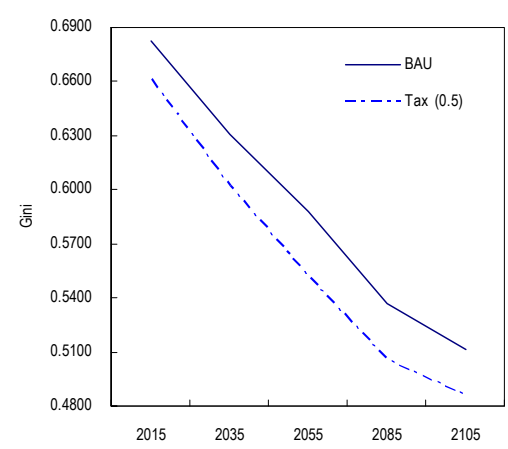

Panel B: Bottom Decile Share

Panel C: Top Decile Share

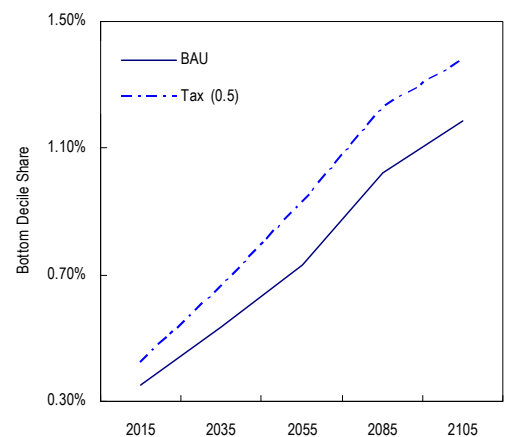

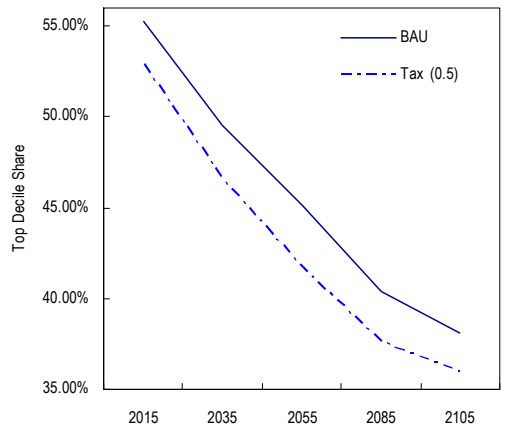

Figure 4 provides a picture of how global inequality and carbon emissions evolve through the period under study. This figure plots the Lorenz curves of global income and redistributed incomes after carbon pricing, together with that of carbon-emissions per capita. We see that the body of the Lorenz curve of income shrinks continuously over time, driven mainly by global economic growth. And in every year, the Lorenz 
curve of the redistributed income is enveloped by the curve for the before carbon pricing case. This reiterates the impact of carbon pricing in equalizing global incomes further, in addition to that from economic growth.

Figure 4: Global Lorenz Curves of Incomes Before and After Redistribution
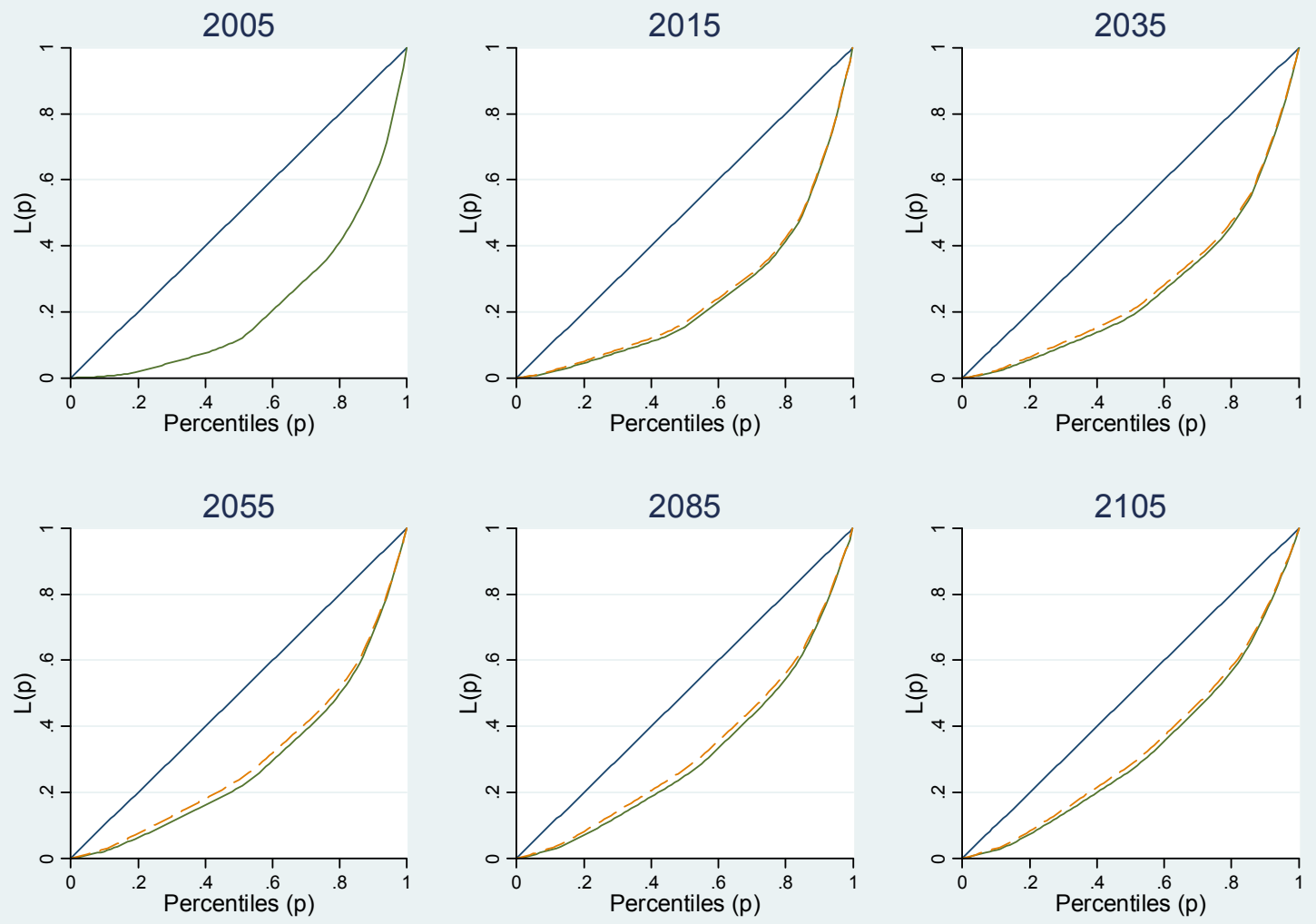

Note: Lorenz curves of global incomes before and after redistributed are plotted in solid and dash lines respectively. There is no carbon pricing and redistribution in 2005.

\subsection{Absolute Poverty Reduction}

Redistributing revenues from carbon pricing not only equalizes income globally, it also provides promising possibilities to reduce or even remove global absolute poverty. In quantifying the impacts of carbon pricing on global absolute poverty reduction, we consider redistribution of revenues in two ways. The first is to redistribute revenues equally on a per capita basis globally. The second is to use a more pro-poor redistribution scheme in which we redistribute a larger share of revenues to the poor. This second 
simulation helps us assess whether such a scheme can help erase all poverty by 2015 , the time line of the Millennium Development Goals (MGDs).

Figure 5 plots the density curves of global income in 2005 US $\$$ PPP terms over time. The vertical line in the figure represents the equivalent poverty line in terms of GDP per capita, at $\$ 911$ (2005 PPP) equivalent to the current Bank World poverty criterion of $\$ 1.25$ (2005 PPP) per day. The area under the curve and to the left of the vertical line calculates the portion of people living in poverty. This times the corresponding world population gives a projection of the number of people living in poverty.

Panel A shows that continued global economic growth will be the key force behind poverty reduction in the next 100 years. The global income distribution moves systematically to the right, with poverty decreasing consistently. This process results in a large reduction in global poverty. From Panel A of Figure 5 the poverty rate in 2105 is small relative to 2005. In addition to the secular poverty reduction driven by growth, carbon pricing contributes to this reduction further, as shown in Panel B of Figure 5, where we use the year 2035 as an example.

The dashed line is the global density curve around the poverty line in the BAU case, which is higher in the far left tail than the solid line describing the density curve of redistributed global income after carbon taxes. This indicates the area under the solid line and to the left of the poverty line is even smaller, as is the poverty rate. Such a pattern also holds for other projection years which we omit for brevity. This suggests carbon pricing has the potential to reduce poverty further in addition to the growth effect.

Using the method given in Section 5, we can also calculate numbers of people living in poverty over time in BAU and carbon-pricing cases. Numbers in both cases and changes in percentage for the BAU case are presented in Table 4. These results suggest that economic growth in the BAU case can reduce poverty substantially over a century, if we adhere to the $\$ 1.25$ (2005PPP) per day criterion. There would be around one billion people globally living in poverty in 2105 if the global economy continues growing as in the BAU scenario. We thus see a very sharp decrease in the population in poverty across time periods, both in BAU and carbon-tax cases, as plotted in Panel A of Figure 6. 
Figure 5: Density Curves Of Global Income Distribution

Panel A: Global Income Distribution Across Time

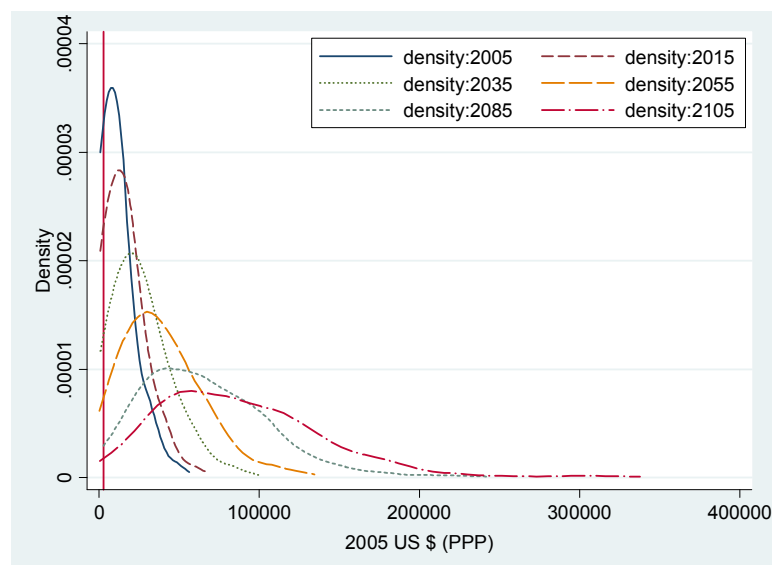

Panel B: Income Distribution Below The Poverty Line Before and After Carbon Pricing (2035)

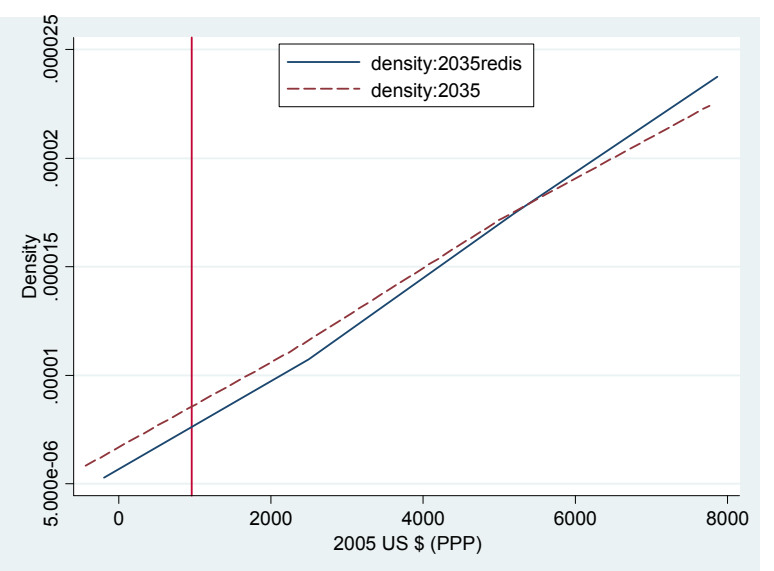

Note: Panel A plots the density curves of global income across 2005, 2015, 2035, 2055, 2085 and 2105 in the BAU case. Panel B plots the density curves of global income around the poverty line before (labeled by density:2035) and after carbon pricing (labeled by density:2035redis) in 2035, in dash and solid lines respectively. The pattern described by Panel B holds for other projection years.

Carbon pricing can also help attain Goal 1 of the Millennium Development Goals (MDGs). In the Millennium Declaration of 2000, 189 nations resolved to "halve extreme poverty by 2015". There are two variants for this target. One is in terms of the share of people in extreme poverty as a percentage of national population, and the other is in terms of the absolute extreme poverty population. Reducing the former is an easier task due to the growth in world population, and several authors even argue we have already attained such a goal (e.g. Bhalla, 2002; Sala-i-Martin, 2002). Our discussions centers on the latter form of target, namely, "halve extreme poverty population by 2015".

The estimated population under the international poverty line was 1.82 billion in 1990(See Table 5 of Chen and Ravallion, 2008). Thus, the primary target of Goal 1 of the MDGs translates to around 0.92 billion people living under the international poverty line by 2015 (UN, 2010). Our results in Table 4 indicate that this target can only be met by around $88 \%\left(=\frac{1.82-1.02}{1.82 \times 0.5}\right)$ by 2015 if there is no carbon pricing. However, combining economic growth and carbon pricing, we can surpass this target by around $6.6 \%\left(=\frac{1.82-0.85}{1.82 \times 0.5}-1\right)$. 
Table 4: Numbers Of Population Living In Poverty And Changes

\begin{tabular}{lrrr}
\hline Year & \multicolumn{1}{c}{ BAU } & Tax & Change \\
\hline 2015 & $1,018,140,019$ & $852,772,758$ & $-16.24 \%$ \\
2035 & $383,141,322$ & $257,904,611$ & $-32.69 \%$ \\
2055 & $99,127,246$ & $46,424,115$ & $-53.17 \%$ \\
2085 & $7,235,425$ & $2,451,849$ & $-66.11 \%$ \\
2105 & $1,027,082$ & 320,163 & $-68.83 \%$ \\
\hline
\end{tabular}

Note: These results are estimated by assuming Lognormal distribution for global income. The estimation procedure is given in the Methodology section.

Figure 6: Population in Poverty and Its Difference Between Cases, 2015 - 2105

Panel A: Numbers in BAU and Carbon Tax Cases Panel B: Difference as Percentage of BAU Case
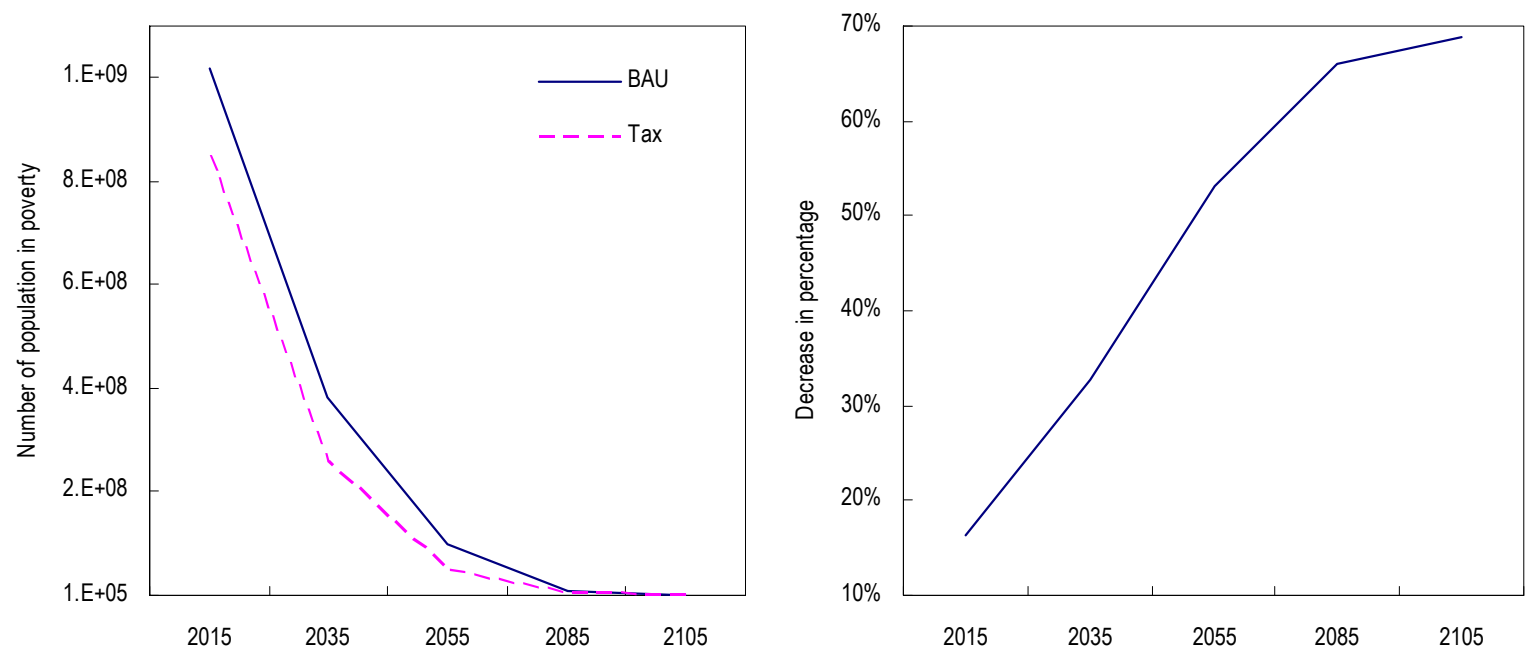

Going one step further, one may ask whether we could erase global poverty entirely by 2015 if we use the carbon taxes revenues for global poverty reduction. Our results suggest we only need around $33 \%$ of the revenues to achieve this goal. Figure 7 plots the population remaining in poverty versus portions of carbon pricing revenues transferred to the poor. In the case where carbon pricing revenues are redistributed on a per capita basis, we transfer around $12 \%$ of the carbon pricing revenues to those under the international poverty line. This helps achieve and even surpasses the goal of halving population in poverty by 2015. If we use a mechanism which transfers more carbon pricing revenues to the poor while keeping those just marginally above the poverty line from falling below, 
we see a steady decrease in the global population in poverty as shown in Figure 7 . The world could achieve the more ambitious goal of erasing global poverty by 2015 if such a mechanism were used.

Figure 7: Poverty Population Changes With Portion of Carbon Pricing Revenues Transferred To The Poor By 2015

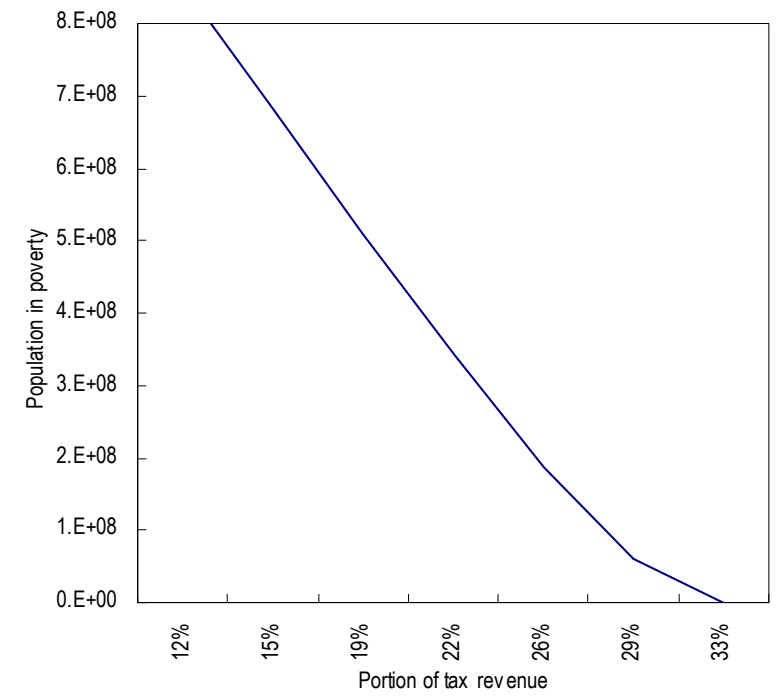

\subsection{Assessing the Anti-poor Nature of Carbon Pricing on the Production Side}

We can also use our analysis to evaluate the anti-poor properties of carbon pricing from both the revenue and production sides. Since emissions intensity of production is sharply higher in low income countries, they bear proportionally more of the tax burden before revenues redistribution enters.

Figure 8 plots the country-level median carbon-emissions per capita and per dollar GDP by income quintiles (in terms of GDP per capita) for the year 2035. The patterns in Figure 8 remain constant until 2055. Panel A of Figure 8 shows that emissions per capita increase with income. The richer a country is, the larger carbon-emission per capita it has but emissions intensity of GDP falls. Median carbon emissions per capita in the fifth quintile countries are 3.43 Metric Tons (in carbon) in 2035, 6.06 times the median in the first quintile countries which is only 0.57. Carbon pricing is thus pro-poor in absolute 
terms on the production side but in proportion to income is pro-rich.

Panel B of Figure 8 shows that emissions per dollar of GDP are nonmonotonic in GDP per capita. From the first quintile to the third quintile, there is an increase with income; but from the third quintile to the fifth quintile a decrease. This reflects the fact that rapidly growing developing countries like China and India located in the third quintile emit heavily due to their growth. In contrast, the poorer countries in the left tail have fewer factories and lower emissions per dollar of GDP. Meanwhile, richest countries in the right tail have smaller emissions intensity due to high energy efficiency and a shift away from heavily emitting manufacturing in recent decades.

Figure 8: Carbon Emissions (in Metric Tons Carbon) by GDP Per Capita Quintile (2035)

Panel A: Carbon Emissions Per Capita

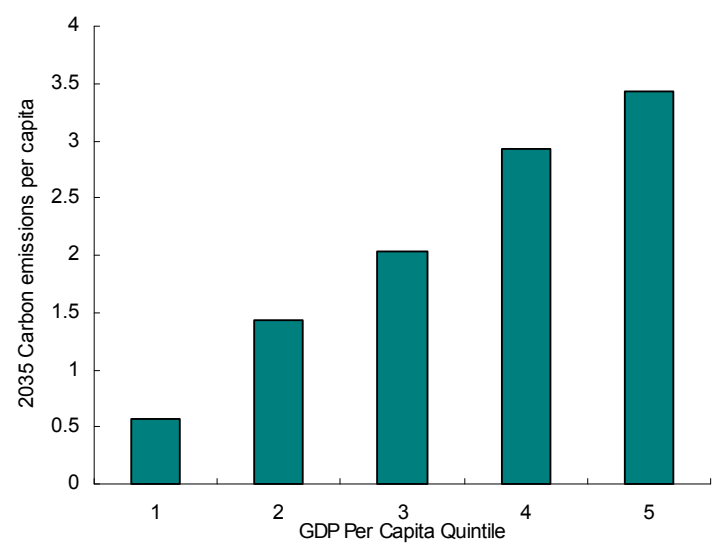

Panel B: Carbon Emissions Per Dollar GDP

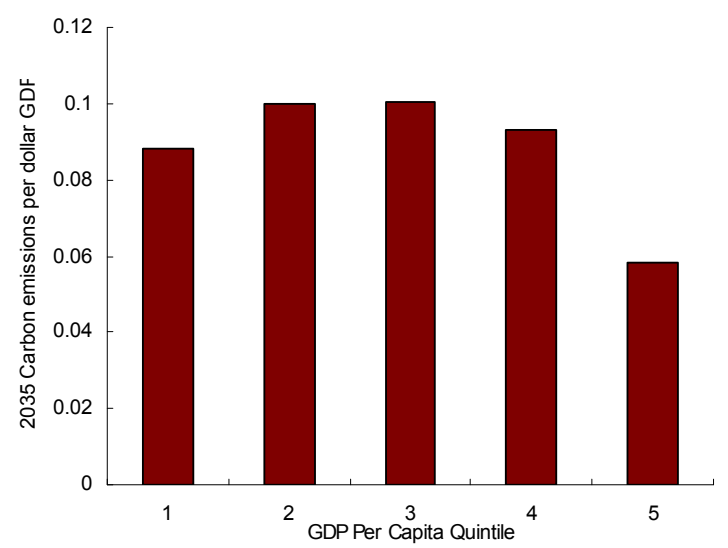

We use Kakwani's (1976) method to quantify the degree of propoorness of global carbon pricing on the production side. Let $G_{1}[T(x)]$ and $G_{1}[R(x)]$ be proportion of carbon pricing and redistributed revenues by the units having income less than or equal to $x . G(x)$ is the distribution function of income $x$. The pairs $G_{1}[T(x)]$ vs. $G(x)$ and $G_{1}[R(x)]$ vs. $G(x)$ form the concentration curves of taxes and redistribution respectively. The concentration index is equal to one minus twice the area under the concentration curve. We denote $C_{T}$ and $C_{R}$ as concentration indices of effective carbon taxes and revenues redistribution of our carbon pricing respectively. Following Kakwani (1976) yields measures of propoorness from both the production side and revenues redistribution 
as follows:

$$
\begin{aligned}
& V_{T}=C_{T}-G, \\
& V_{R}=C_{R}-G,
\end{aligned}
$$

where $P_{T}$ and $P_{R}$ denote propoorness indices of tax obligation and revenues redistribution respectively, $G$ is the Gini coefficient of before-tax income. A positive propoorness index indicates the tax scheme is pro-poor.

Summing equations 15 and 16 gives an overall propoorness index $P$ as

$$
V=C_{T}+C_{R}-2 G
$$

Table 5 reports results of $V_{T}, V_{R}$ and $V$ for respective projection years, with Figure 9 plotting their trajectories. It shows that our central carbon pricing scheme displays a strongly pro-poor property in absolute terms as values of $V$ are all very much larger than zero. The redistribution effect suggested by positive values of $V_{R}$ together with negative $V_{T}$ before 2055 indicates the mixed progressiveness and regressiveness for the effective carbon tax obligations.

Table 5: Propoorness Measurements of Our Central Carbon Pricing

\begin{tabular}{lccc}
\hline Year & $V_{T}$ & $V_{R}$ & $V$ \\
\hline 2015 & -0.1839 & 0.5005 & 0.3166 \\
2035 & -0.0954 & 0.5807 & 0.4853 \\
2055 & -0.0135 & 0.6226 & 0.6091 \\
2085 & 0.0649 & 0.7044 & 0.7693 \\
2105 & 0.1020 & 0.7166 & 0.8185 \\
\hline
\end{tabular}

\subsection{Carbon-Pricing Schemes with Elasticity and Energy Im- provement Sensitivity}

As sensitivity analysis on our results, we consider variants around the central carbon pricing scheme by varying the elasticity and efficiency factors respectively across plausible values. 
Figure 9: Kakwani Indices For Our Central Carbon Pricing Scheme

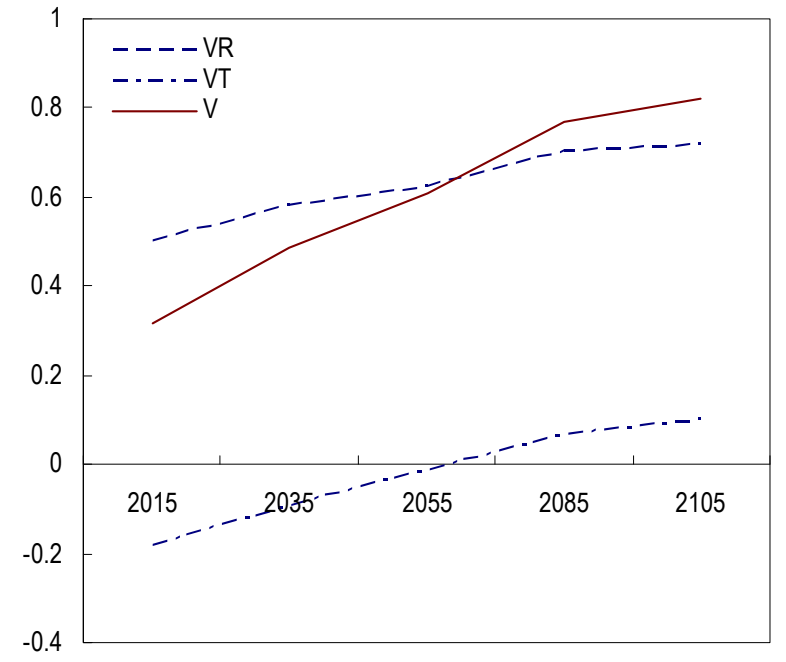

In our central case, we use a demand elasticity for fossil fuels of -0.5 . Our variants suppose it changes to -0.6 and -0.7 respectively. Figure 10 depicts how these variations impact global relative inequality reductions (the elasticity value is in the brackets in the legends). The relative inequality reduction of carbon pricing is a decreasing function of the elasticity, any of the Gini coefficients or changes in top and bottom decile shares. The bottom decile share is the most sensitive to the changes in elasticity.

Figure 10: Elasticity Sensitivity Analysis on Relative Inequality Reduction

Panel A: Gini

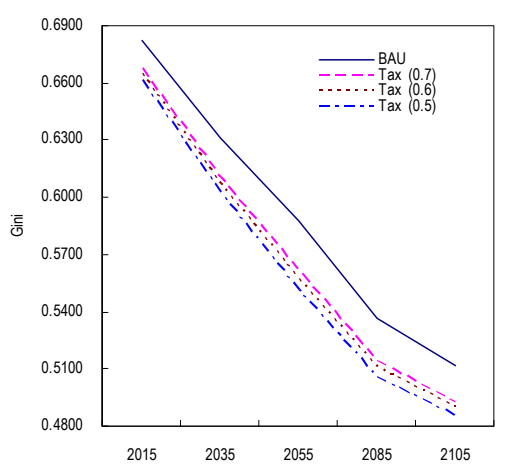

Panel B: Bottom Decile Share

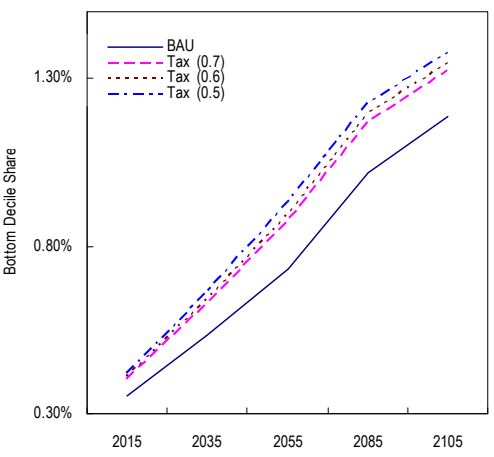

Panel C: Top Decile Share

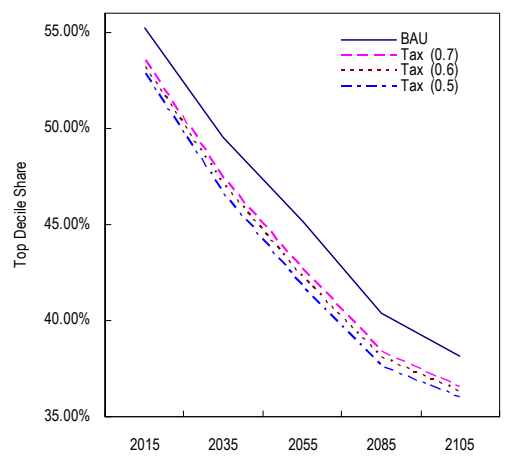

Figure 11 plots the impacts on global absolute poverty reduction from elasticityvariation. Absolute poverty reductions from carbon pricing diminish substantially due to reduced tax revenues collected with a lower tax rate when the elasticity increases. With an elasticity of -0.7 , which collects the least carbon tax revenue among our variants, we 
still see the primary MDG goal, Goal 1, could be attained by 2015. In this case, the global population in poverty is projected to be 0.89 billion by 2015 , which also surpasses the stated goal in the MDGs.

Figure 11: Elasticity Sensitivity Analysis Regarding Absolute Poverty Reduction

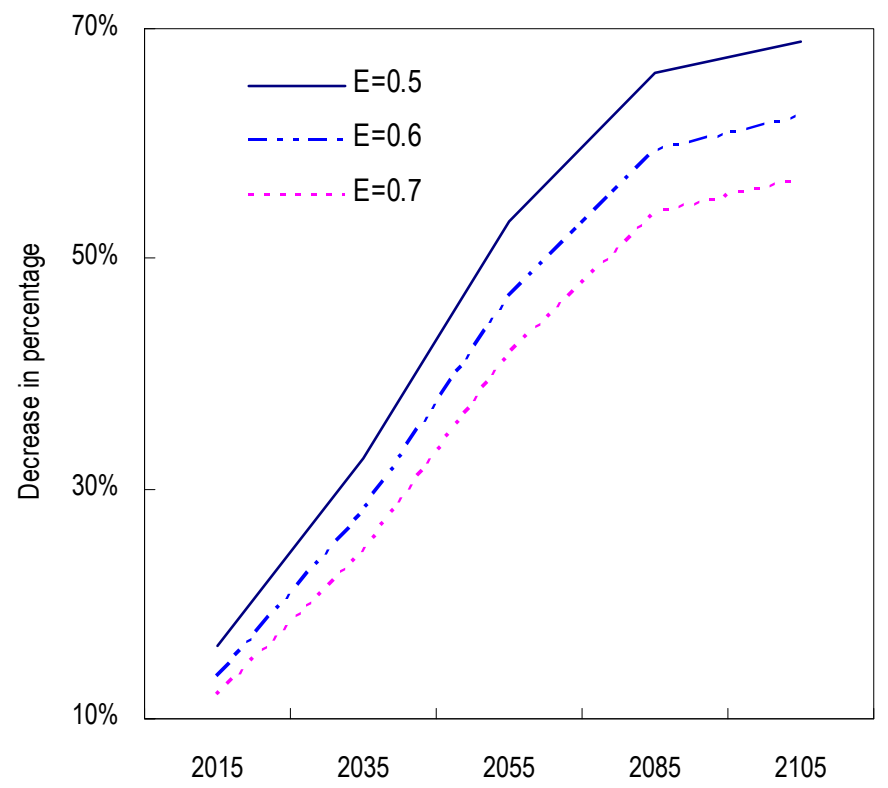

We also conduct sensitivity analysis for the efficiency improvement factors used the BAU and counterfactual cases. We relax this assumption and suppose that the efficiency improving factor in the counterfactual case changes to $3 \%$ and $4 \%$ respectively, while keeping $2 \%$ in the BAU case. We see a similar pattern as in the elasticity sensitivity analysis. Revenues decrease with further efficiency improvment in the counterfactual case. As a result, revenue collected is reduced as are the redistributive effects.

\section{Concluding Remarks}

In this paper, we quantify the potential impacts of full global carbon pricing on global inequality and the implications for global poverty reduction. We use the projections from Nordhaus's (2010) RICE model to set up counterfactual scenarios incorporating a target to limit global temperature increases to less than $2^{\circ} \mathrm{C}$ over a 100 year time frame. We assume a time-stable price elasticity of demand for fossil fuels of -0.5 and identical energy 
efficiency improvement factors across countries in counterfactual scenarios. Fully global carbon pricing yields revenues of $6 \%$ of world gross product over our projection years. The redistributive scheme generates major incremental global poverty reductions in addition to those produced by economic growth. In terms of global relative equalization, this scheme produces extra decreases in the global Gini index and the top decile share no less than $4 \%$ and $2 \%$ respectively, and a more pronounced increase in the bottom decile share of no less than 15\%. Furthermore, using a more pro-poor redistribution scheme which allocates a larger share of revenues to the extreme poor, we find that poverty can be erased by the MDG deadline year of 2015 at a cost of only $33 \%$ of carbon pricing revenues.

\section{References}

[1] Bhalla, S.S., 2002. Imagine There is No Country: poverty, inequality, and growth in the era of globalization, Institute for International Economics, Washington, DC.

[2] Boyce, J.K., Riddle, M.E., 2009. Cap and Dividend: a State-by-State Analysis. Working Paper, Political Economy Research Institute, University of Massachusetts, Amherst.

[3] Chen, S., Ravallion, M., 2008. The Developing World Is Poorer Than We Thought, But No Less Successful In Fighting Against Poverty. World Bank Policy Research Working Paper No. 4703.

[4] Cowell, F.A., 1977. Measuring Inequality. Oxford: Phillip Allan Publishers.

[5] Deaton, A., 2008. How to Monitor Poverty for the Millennium Development Goals. Journal of Human Development 4: 353 - 378.

[6] EIA, 2010. http://www.eia.doe.gov/pub/oil_gas/petroleum/analysis_publications/primer_on_gasoline_prices/html /petbro.html.

[7] Grubb, M. and S. Droege, 2010. A Carbon Giveaway Europe Cannot Afford. Financial Times, June 14. http://www.ft.com/cms/s/0/cfdb84f2-77e8-11df-82c3-00144feabdc0.html.

[8] IEA, 2008. Worldwide Trends in Energy Use and Efficiency : Key Insights from IEA Indicator Analysis. Paris: International Energy Agency.

[9] IIASA (International Institute of Applied Systems Analysis) World Population Program. 2007. Probabilistic Projections by 13 World Regions, Forecast Period 2000-2100, 2001 Revision. Available online at http:// www.iiasa.ac.at/Research/POP/proj01/.

[10] IPCC (Intergovernmental Panel on Climate Change), 2000. Special Report on Emissions Scenarios. Cambridge: Cambridge University Press. 
[11] IPCC (Intergovernmental Panel on Climate Change), 2007. Climate Change 2007: Synthesis Report. IPCC Plenary XXVII, Valencia.

[12] Kakwani, N.C., 1976. Measurement of Tax Progressivity: An International Comparison. The Economic Journal 87: 71-80.

[13] Kemp-Bendict, E., 2001. Income Distribution and Poverty: Methods for Using Available Data in Global Analysis. PoleStar Technical Notes No.4.

[14] Komanoff, C., 2010. Carbon Tax Center (CTC) CARBON TAX_ 4_Sector Model, www.carbontax.org.

[15] Lipow, G.W., Energy Price Demand Elasticity. www.carbontax.org.

[16] Milanovic, B., 2005. Worlds Apart: Measuring International and Global Inequality. New Jersey: Princeton University Press.

[17] Milanovic, B., 2009. Global inequality recalculated: The effect of new 2005 PPP estimates on global inequality. MPRA Paper No. 16538.

[18] Nordhaus, W., 2008, A Question of Balance: Weighing the Options on Global Warming Policies. New Haven \& London: Yale University Press.

[19] Nordhaus, W., 2010, Papers and Files for RICE-2010 Model (May 2010), http://nordhaus.econ.yale.edu/.

[20] Sala-i-Martin, X., 2002. The disturbing "rise" of global income inequality, NBER Working Paper No. 8904, NBER, Cambridge, MA.

[21] Shorrocks, A., and D. Mookherjee, 1982. A Decomposition Analysis of the Trend in UK Income Inequality. The Economic Journal 92: 886-902.

[22] Stern, N., 2007. The Economics of Climate Change: The Stern Review. Cambridge: Cambridge University Press.

[23] UN (United Nations), 2007. Expert Group on Energy Efficiency, 2007: Realizing the Potential of Energy Efficiency: Targets, Policies, and Measures for G8 Countries. Washington: United Nations Foundation.

[24] UN (United Nations), Millennium Development Goals. http://www.un.org/millenniumgoals/.

[25] UN (United Nations) United Nations. Department of Economic and Social Affairs, Population Division. 2004. World Population to 2300. ST/ESA/SER.A/236. New York: United Nations. 